\title{
Left atrial function in left bundle branch block: volumetric measurements of its function
}

\author{
Fatmir Ferati ${ }^{*}$, \\ Anida Ferati ${ }^{2}$, Ardian \\ Preshova ${ }^{2}$, Mentor \\ Karemani $^{2}$ \\ 'University Hospital \\ Tetovo, Tetovo, Republic of \\ Macedonia \\ ${ }^{2}$ Med-Artis, Tetovo, Republic \\ of Macedonia
}

\begin{abstract}
KEYWORDS: left bundle branch block, left atrial function, left ventricular systolic dyssynchrony index left atrial ejection fraction.

CITATION: Cardiol Croat. 2017;12(4):129. | https://doi.org/10.15836/ccar2017.129

*ADDRESS FOR CORRESPONDENCE: Fatmir Ferati, University Hospital Tetovo, Derish Cara bb, 1200 Tetovo, Republic of Macedonia. / Phone: +389-70-224138 / E-mail: fatmir_ferati@yahoo.com

ORCID: Fatmir Ferati, http://orcid.org/0000-0001-8189-316X • Anida Ferati, http://orcid.org/0000-0002-4243-5569 Ardian Preshova, http://orcid.org/0000-0003-2416-6593 • Mentor Karemani, http://orcid.org/0000-0001-6626-6504
\end{abstract}

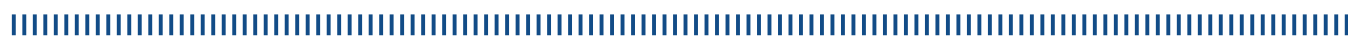

TABLE 1. Echocardiographic values according to the presence of left bundle branch block.

\begin{tabular}{lccc} 
VARIABLE & $\begin{array}{c}\text { WITHOUT } \\
\text { LBBB }\end{array}$ & WITH LBBB & $\begin{array}{c}\mathbf{p} \\
\text { value }\end{array}$ \\
\hline EF LV (\%) & 60.81 & 38.33 & $<0.001$ \\
\hline GLS LV (- \%) & 18.5 & 11.807 & $<0.001$ \\
\hline GCS LV (\%) & 30.86 & 26.57 & $<0.001$ \\
\hline SDI LV (\%) & 3.4 & 10.07 & $<0.001$ \\
\hline EF LA & 69.9 & 71.38 & $<0.001$ \\
\hline ESVLA (ml/m $\left.{ }^{2}\right)$ & 30.1 & 45.15 & $<0.001$ \\
\hline EDVLA (ml/m ${ }^{2}$ ) & 6.5 & 12.53 & $<0.001$ \\
\hline dV/dTof EDAEV (ml/sec $\left.{ }^{2}\right)$ & 221.5 & 95.46 & $<0.001$ \\
\hline dV/dT of ACEV (ml/sec $\left.{ }^{2}\right)$ & 135.8 & 203.46 & $<0.001$ \\
\hline dV/dT EDAEV / dV/dT ACEV & 1.63 & 0.46 & $<0.001$ \\
\hline (\%) & & & \\
\hline EDAEV(ml/m $\left.{ }^{2}\right)$ & 20.66 & 9.23 & $<0.001$ \\
\hline ACEV (ml/m $\left.{ }^{2}\right)$ & 10 & 23.84 & $<0.001$ \\
\hline EDAEV/ACEV index (\%) & 2.1 & 0.4 & $<0.001$ \\
\hline RR interval (msec) & 780 & 744.53 & $<0.001$ \\
\hline SET (msec) & 333.333 & 504.76 & $<0.001$ \\
\hline SET/RR interval index (\%) & 0.42 & 0.69 & $<0.001$ \\
\hline
\end{tabular}

$L B B B=$ left bundle branch block; $L V=$ left ventricle; $L A=$ left atrium; $E F$ of $L V=$ ejection fraction of $L V ; G L S$ of $L V=$ global systolic strain of $L V ; G C S$ of $L V=$ global circumferential strain of LV; SDI of LV = systolic dyssynchrony index of LV; EF LA = ejection fraction of $L A ; E S V L A=$ end systolic volume of $L A$; EDVLA $=$ end diastolic volume of $L A$; EDAEV = early diastolic atrial emptying volume; $A C E V=$ atrial contraction emptying volume; $S E T$ = systolic expansion time of $L A$.

Introduction: The aim of this study was to analyze the function of left atrium (LA) ${ }^{1}$ in patients with left bundle branch block (LBBB).

Patients and Methods: 20 patients without verified cardiovascular disease and 20 with LBBB were examined for left ventricular (LV) and LA function quantification.

Results: We obtained lower values of EF of LV, 38.33\% in patients with LBBB, against $60.81 \%$ in patients without LBBB (Table 1). The global systolic strain of LV in patients without LBBB was $18.50 \%$ against $11.80 \%$ of the group with LBBB. The global circumferential strain of LV in patients without LBBB was $30.86 \%$ compared to $26.57 \%$ in patients with LBBB. EF of LA was $69.9 \%$ in patients without LBBB compared to $71.38 \%$ in patients with LBBB. The endsystolic volume of LA (ESVLA) in patients without LBBB was $30.1 \mathrm{ml} / \mathrm{m}^{2}$ compared to 45.5 $\mathrm{ml} / \mathrm{m}^{2}$ in patients with LBBB. The enddiastolic volume of LA (EDVLA) in patients without LBBB was $6.5 \mathrm{ml} / \mathrm{m}^{2}$ compared to $12.53 \mathrm{ml} / \mathrm{m}^{2}$ in patients with LBBB. LA function timing intervals, expressed through dV/dT of early diastolic atrial emptying volume (EDAEV) in patients without LBBB was $221.5 \mathrm{ml} /$ $\mathrm{m}^{2}$ compared to $95.46 \mathrm{ml} / \mathrm{m}^{2}$ in patients with LBBB, whereas $\mathrm{dV} / \mathrm{dT}$ of atrial contraction emptying volume (ACEV) in patients without LBBB was $135.8 \mathrm{ml} / \mathrm{m}^{2}$ compared to $203.46 \mathrm{ml} /$ $\mathrm{m}^{2}$ in patients with LBBB. The dV/dt of EDAEV and ACEV ratio is 1.63 in patient without LBBB against 0.46 in patients with LBBB. EDAEV in patients without LBBB was $20.66 \mathrm{ml} \mathrm{com-}$ pared to $9.23 \mathrm{ml}$ in patients with LBBB, whereas the ACEV for the group without LBBB was $10 \mathrm{ml}$ compared to $23.84 \mathrm{ml}$ for the group with LBBB. The EDAEV/ACEV ratio for patients without LBBB was 2.1 compared to 0,4 for the group with LBBB. The systolic expansion time of LA (SET) was $333.33 \mathrm{msec}$ vs 504.76 msec of subjects with LBBB, whereas the RR interval (msec) in patients without LBBB was 780 msec against 744.53 msec in patients with LBBB. The ratio between the LA (SET)

\section{RECEIVED:}

February 6, 2017

ACCEPTED:

April 6, 2017

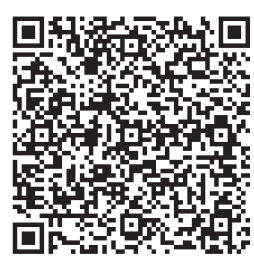

and the RR interval (SET/RR interval index) for the group without LBBB was 0.42 against 0.69 for the group with LBBB.

Conclusions: A) LBBB does not have influence on the value of EF of LA but in dynamic of atrial functioning. B) LBBB causes reduction of EF of VM. C) LBBB causes an increase of ESVLA and EDVLA of the LA. D) LBBB reduces EDAEV and increase ACEV. E) LBBB increases ACEV. F) LBBB causes elongation of the SET of LA.

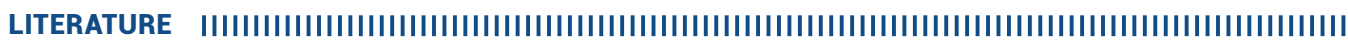

1. Clarkson PB, Wheeldon NM, Lim PO, Pringle SD, MacDonald TM. Left atrial size and function: assessment using echocardiographic automatic boundary detection. Br Heart J. 1995;74(6):664-70. https://doi.org/10.1136/hrt.74.6.664 